\title{
Temporal range of apparent movement as a function of age and intelligence
}

The temporal range of interstimulus intervals permitting the report of the apparent movement of a square was investigated as a function of chronological age and intelligence. Both the range and the succession to movement threshold were found to decrease from age 6 through 9 , and then to increase through age 11. Although correlation with IQ was positive and significant overall, it was higher in the older children.

Apparent movement, like backward figural masking (Pollack, 1965) represents a situation in which there is conflict between the phenomena observed and the facts of physical stimulus presentation. In both cases, two stimuli are presented in discrete succession separated by distance, but the phenomena reported are either simultaneous presentation of target and mask or a single object moving across a field. Although the interstimulus intervals are similar in the two situations (up to about $150 \mathrm{msec}$ ), the greater and unilateral spatial separation in apparent movement provides the feeling of continuing position change. It is possible, therefore, that the phenomenon of apparent movement may be intermediate between those illusory phenomena which depend upon apparent simultaneity of figural parts for their occurrence, e.g., Mueller-Lyer illusion (Type 1, Pollack, 1964), and those which depend upon apparent succession with their implied dependence upon successive comparison, e.g., successively presented parts of the Mueller-Lyer figure (Type II, Pollack, 1964). If apparent movement is such a transitional phenomenon, then its ontogenetic course would not be monotonic. As the stimulus variables involved, figure-ground contrast, contour orientation, stimulus duration (Pollack, 1966a, b) lose their potency with increasing age (Pollack, 1963), the temporal range of apparent movement between perceived simultaneity and perceived discrete succession would be expected to shrink. If, by contrast, some mechanism of temporal comparison of successive stimuli were to become increasingly available with increasing age, then at some point the range of apparent movement might be expected to grow once again. Such an inflected ontogenetic curve was found to occur for the frequency of occurrence of figural aftereffects following brief fixations (Pollack, 1960). Inflection took place at about age 9 .

\section{Subjects $^{1}$}

Seventy-two children, six boys and six girls at each of the ages $6,7,8,9,10$, and 11 served as naive Ss. Apparatus

The apparent movement sequence was produced by using a three-channel electronic tachistoscope (Scienti- fic Prototype Corporation, Model GA). Illumination as measured at the eyepiece by a Macbeth Illuminometer was $5.0 \mathrm{ft}$. c. for all channels.

\section{Procedure}

The initial stimulus, a white square $12.7 \mathrm{~mm}$ on a side placed $6.35 \mathrm{~mm}$ to the left of the center of a black field, was presented for $150 \mathrm{msec}$. The final stimulus, an identical white square placed $6.35 \mathrm{~mm}$ to the right of the center of a black field was presented for $50 \mathrm{msec}$. The interstimulus distance subtended a visual angle of $39^{\prime} 40^{\prime \prime}$ and the total display subtended an angle of $2^{\circ}$. A blank black field intervened for a 10-150 msec. variable interval between the two stimuli. Viewing was binocular.

Upper and lower apparent movement thresholds were obtained from all subjects using the method of limits, four ascending and four descending counterbalanced series.

In sequence, Ss were shown instances in which the stimuli were clearly successive, moving or clearly simultaneous. They were told to say "two" when the figures were successive or simultaneous or "one" when a single figure was seen to move from left to right.

\section{Results and Discussion}

The data indicated that the range of apparent movement did shrink up through age 9 and then increased up to age 11 (see Fig. 1). Analysis of variance showed that the age changes were significant $(F=2.65, \mathrm{df}=5 / 66$, $\mathrm{p}<.05)$. A test for trend indicated significant deviation from linearity. The equation of best fit was quadratic

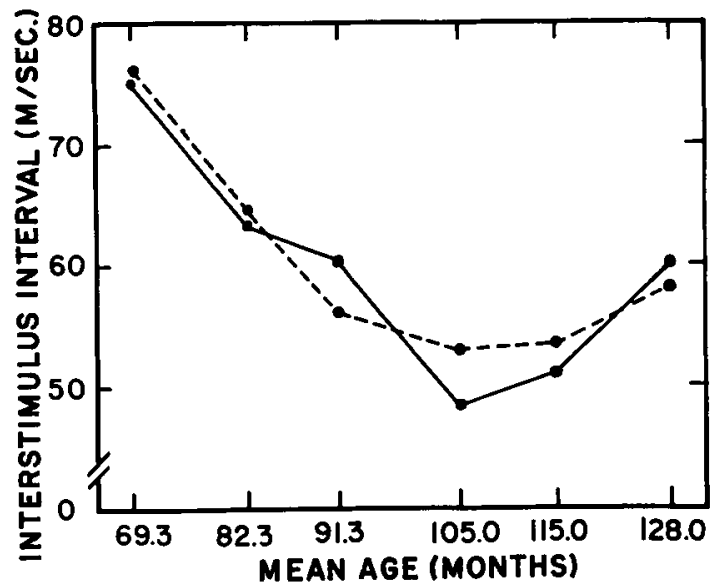

Fig. 1. Mean range of interstimulus interval times permitting the report of apparent movement as a function of age. The solid line represents empirical data; the dotted line represents the curve of best fit. 


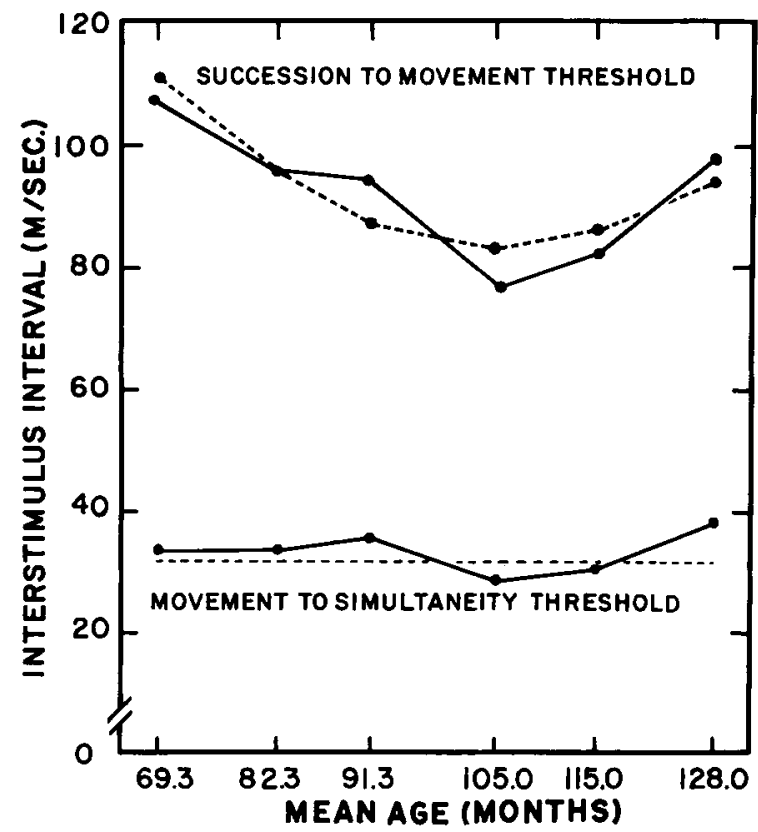

Fig. 2. Mean succession to movement and movement to simultaneity thresholds as a function of age. The solid lines represent empirical data; the dotted lines represent the curves of best fit-

$\left(\mathrm{Y}=92.94-18.73 \mathrm{X}+2.16 \mathrm{X}^{2}\right)$. Analysis of the threshold between succession and movement as a function of age yielded a similar result $(F=4.01, \mathrm{df}=5 / 66, p<.01)$ also with a quadratic equation for the curve of best fit $(Y=$ 132.35-23.92X $+2.94 \mathrm{X}^{2}$ ). In contrast, analysis of the threshold between movement and simultaneity yielded an $F$ ratio of only .96 , and there was no significant trend. The line of best fit is horizontal (see Fig. 2).

Correlations of IQ (Lorge-Thorndike) with range of apparent movement and succession-movement threshold were positive (.25 and .24) and significant (df $=56$, $\mathrm{p}=.05) .{ }^{2}$ In order to test indirectly the contention that the change in the direction of the age trend reflected a greater involvement of intellectual functioning (suc- cession-comparison) in the older children, the correlations between range and $\mathrm{IQ}$, and succession-movement threshold, and IQ for ages 7-9 ( $\mathrm{r}=-.06,-.12)$ were compared with those for ages $10-11(r=.25, .37)$. The correlation at ages 10-11 was significantly higher ( $p<.05$-one tailed test). It is possible, therefore, that the process underlying the phenomenon of apparent movement changes sometime after age 9 , and the change defines the border between Type I and Type II phenomena. ${ }^{3}$

\section{References}

Brenner, M. W. The developmental study of apparent movement. J. exp. Psychol., 1957, 9, 169-174.

Gantenbein, M. Recherches sur le développement, de la perception du mouvement avec l'age (mouvement apparent, dit stroboscopique). Arch. Psychol. Genève, 1952, 33, 197-294.

Meili, R., \& Tobler, E. Les mouvements stroboseopiques chez les enfants. Arch. Psychol. Genève, 1931, 23, 131-156.

Pollack, R. H. Figural after-effect as function of age. Acta Psychologica, 1960, 17, 417-423.

Pollack, R. H. Contour detectability thresholds as a function of chronological age. Percept. mot. Skills, 1963, 17, 411-417.

Pollack, R. H. Simultaneous and successive presentation of elements of the Mueller-Lyer figure and chronokogical age. Percept. mot. Skills, 1964, 19, 303-310.

Pollack, R. H. Backward figural masking as a function of chronological age and intelligence. Psychon. Sci., 1965, 3, 65-66.

Pollack, R. H. Effect of figure-ground contrast and contour orientation on the temporal range of apparent movement. PsychonSci., 1966a, 4, 401-402.

Pollack, R. H. Initial stimulus duration and the temporal range of apparent movement. Psychon. Sci., 1966b, 4 ,

\section{Notes}

1. Acknowledgement is made to Mr. Gene Lubera, Principal of Arbor View School, District 89, Glen Ellyn, Illinois, to his staff. and to the district superintendent for their cooperation in providing Ss, space and encouragement.

2. There were no scores available for kindergarten children. 3. The author is well aware of the work of Meili \& Tobler (1931), Gantenbein (1952), and Brenner (1957) on apparent movement and age. The studies cited differed from the above in that visual angles were considerably larger, the stimulus sequences were repeated continuously, uncontoured lights served as stimuli, and temporal range was not measured. Direct comparison is therefore not possible. 